
\title{
28 Research Square \\ Tracing the origin, evolutionary history, and biological functions of CKI genes: a focus on Gossypium spp
}

\section{Yaoyao Li}

National Key Laboratory of Crop Genetic Improvement, Huazhong Agricultural University

\section{Yanlong Li}

National Key Laboratory of Crop Genetic Improvement, Huazhong Agricultural University

\section{Yuanyuan Chen}

National Key Laboratory of Crop Genetic Improvement, Huazhong Agricultural University

\section{Maojun Wang}

National Key Laboratory of Crop Genetic Improvement, Huazhong Agricultural University

\section{Xianlong Zhang}

National Key Laboratory of Crop Genetic Improvement, Huazhong Agricultural University

\section{Longfu Zhu}

National Key Laboratory of Crop Genetic Improvement, Huazhong Agricultural University

Ling Min ( $\nabla$ lingmin@mail.hzau.edu.cn )

Huazhong Agriculture University https://orcid.org/0000-0003-4278-0626

\section{Research article}

Keywords: Casein kinase I, Cotton, Evolutionary history, Gene expression

Posted Date: July 16th, 2020

DOl: https://doi.org/10.21203/rs.3.rs-37359/v1

License: (c) (i) This work is licensed under a Creative Commons Attribution 4.0 International License. Read Full License 


\section{Abstract}

Background: Casein kinase I (CKI) is a kind of serine/threonine protein kinase highly conserved in plants and animals. Although molecular function of individual member of CKI family has been investigated in Arabidopsis, little is known about their origin and evolutionary history in the plant kingdom.

Results: In this study, seven representative plant species (with a focus on cotton) are applied to study gene family evolution and characterize the origin of $C K /$ genes. Three important insights were gained: (i) the ancestral $C K I$ genes were traced back to 250 million years ago; the family expansion occurred in different plant species through independent genome duplication events; (ii) the $C K I$ genes were classified into two types, on the basis of their structural characteristics; (iii) expression profile analysis revealed that cotton $C K /$ genes had various expression patterns in different tissues and exhibited inducible expression in response to photoperiod (circadian clock), light signal and heat stress during cotton anther development.

Conclusion: This study provides genome-wide insights into the evolutionary history of cotton $C K I$ genes and lays a foundation for further investigation of their roles in specific developmental processes and/or environmental stress conditions.

\section{Background}

Casein kinase I (CKI) is a serine/threonine specific protein kinase, highly conserved in plant and animal species [1-3]. In mammals, structural analysis of the CKI proteins had showed that the kinase domains were highly conserved, but the length and primary structure of their $\mathrm{N}$-terminal and C-terminal noncatalytic domains were highly diverse [3]. Compared to other protein kinases, CKI proteins contain four short conserved peptides: HIPXR, LPWQGLKA, EXSRRDD, and LLGPSLEDLF [4].

Due to the broad distribution of the $C K I$ gene family members and their substrates, $C K I$ genes have been found to participate in many biological activities. In yeast, CKI plays important roles in gene expression regulation, vesicle trafficking, cell morphogenesis, cell cycle, cell colonization, and DNA repair [5-8]. In mammals, CKI is involved in cell proliferation, cytokine production, and the transduction and regulation of a variety of signaling pathways related to apoptosis and tumor production and development, such as Wnt and Hedgehog [9-11]. In plants, it has been reported that several $C K /$ genes have important functions in the regulation of a variety of biological processes related to growth and development, as well as various responses to environmental stimuli [12]. In rice, abscisic acid (ABA) and brassinolide (BR) caused upregulation of OSCKI1, while OsCKI1 deficiency caused shorter primary roots and fewer lateral and adventitious roots [2]. Early flowering 1 (EL 1)// Heading date 16 (Hd16),, a CKI, regulated the rice flowering pathway by enhancing the photoperiod response caused by the phosphorylation of DELLA protein SLR1 and Ghd7 [13-14]. In Arabidopsis, the casein kinase I-like (AtCKL) AtCKL2 and AtCKL3, are necessary for ABA to regulate seed germination, root growth and gene expression [15-17], and overexpression of either AtCK1.3 or AtCK1.4 delayed flowering under long-day conditions in Arabidopsis [18]. In addition, MLK3, a 
Plant-specific Casein Kinase 1, is critical for maintaining proper flowering time [19]. In cotton, GhCKI was speculated to regulate not only tapetal programmed cell death (PCD) and anther dehiscence [20], but also somatic embryogenesis by modulating auxin homeostasis [21]. Since the functions of most $C K I$ genes in higher plants are largely unknown, their identification and characterization are particularly relevant for understanding their role and to potentially employ them as genetic resources for improving crop plant defense against biotic and abiotic stresses. In cotton, no genome-wide characterization of the $C K /$ gene family has been reported so far. However, the recently published cotton species genomic information is a solid foundation for characterizing $C K I$ genes at a genome-wide level. Here we have investigated several fundamental questions regarding the $C K I$ gene family evolution: (i) the evolutionary expansion of the $C K I$ gene family; (ii) the diversity of gene structure and domain architecture; and (iii) expression profiles of the $C K I$ genes under different conditions. In summary, we retraced the evolution of the $C K I$ genes to better understand their essential elements and thus be able to exploit this knowledge for plant growth and development.

\section{Results}

Identification and Classification of the Casein Kinase I(CKI) in Gossypium

To extract CKI sequences, BLASTP searches of the complete genomes of three sequenced cotton species (G. raimondii, G. arboreum, and G. hirsutum acc. TM-1) [22-24] were implemented using the homologybased method with 13 Arabidopsis CASEIN KINASE 1-LIKE (CKL)and HEADING DATE 16 (Hd16, a CKI protein) encodes as queries. As a result, 31, 30, and $61 \mathrm{CKI}$ members were identified in $\mathrm{G}$. raimondii (D genome), G. arboretum (A genome) and G. hirsutum (AD genome), respectively (Table 1). We named the 31 G. raimondii $C K I$ genes GrCKI1 to GrCKI31. Considering G. hirsutum is an allotetraploid cotton species which contains $A$ and $D$ genomes, we named the 61 putative $G$. hirsutum $C K /$ genes as GhCKI1A/D to GhCKI31A/D, following the same nomenclature system applied to $G$. raimondii $C K /$ genes. To get a better understanding of the phylogenetic relationships between CKIs, an unrooted phylogenetic tree was generated using the CKI protein sequences from G. raimondii, G. arboreum and G. hirsutum acc. TM-1 (Figure 1). The CKIs were classified into type I and II. A homolog of most $C K I$ genes can be found once in the diploid G. raimondii, once in G. arboretum, and in two copies in the tetraploid G. hirsutum acc. TM-1 (Table 1). The inconsistent presence of single homologous genes among these cotton species might result from gene gains or losses during their individual evolution process or from assembly errors in partial chromosomal regions, which need to be further confirmed.

Tetraploid cotton species such as $G$. hirsutum $L$. are thought to have formed by a polyploidization event that occurred approximately 1-2 million years ago, which involved $D$ and $A$ genome species (Wendel, 1989) [25]. The sequenced D-progenitor genome ( $G$. raimondii) has been well assembled and annotated and its co-linearity with $G$. hirsutum acc. TM-1 genome resulted obvious [22, 24]. Consequently, $G$.

raimondii genome information was used to characterize the $C K I$ family genes. The phylogenetic tree was independently constructed using the MEGA 6 software (Figure S1). All G. raimondii CKI proteins fell into two distinct groups, which was consistent with the results of Figure 1. The type I CKI proteins were further 
divided into three subclasses: Group A, B, and C; the type II CKI proteins were classified into two subclasses: Group D and Group E (Figure S1 and Table S1).

\section{Gene Structure, Conserved Motifs and Domains of CKI Genes in G. raimondii}

The gene structures were related to their roles. Hence, the gene structure of CKI proteins in G. raimondii were investigated. The putative conserved domains of GrCKI proteins were found using the online program Conserved Domain Search Service (http://www.ncbi.nlm.nih.gov/Structure/cdd/wrpsb.cgi). The type I GrCKI proteins were highly conserved within their kinase domains, but differed significantly in the length and primary structure of their N-terminal (8-53 aa) and C-terminal domains (176 aa up to more than 206 aa) (Figure 2a, Figure S2a). The gene structure of type I GrCKI proteins was consistent with previous reports $[3-4,26]$. The type II GrCKI proteins also presented conserved kinase domains. However, contrary to the type I GrCKI proteins, type II possessed a variable N-terminal (1-159 aa) and conserved Cterminal (278-355 aa) (Figure 2b and Figure S2b). In addition, several short sequences are absolutely conserved among the CKIs and not found in other kinases. To further confirm whether the conserved fragments are present in type I and II GrCKI proteins, sequence alignment was performed. The result showed type I GrCKI proteins possess the four short sequences LLGPSLEDLF, HIPXR, EXSRRDD, and LPWQGLKA (Figure 2c). Type II GrCKI proteins contained three of the four conserved sequences (LGPSL, SRRDD, and LPWQG). However, compared with the type I CKI proteins, two specific fragments LGKGGFGQV and HGDVKPEN were present in the type II GrCKI proteins only. Comprehensively, LGPSL, SRRDD, and LPWQG appeared in both type I and type II GrCKI proteins.

The 3D structure of GrCKI proteins was predicted by the software SWISS-MODEL (https:// swissmodel.expasy.org) [27]. The 3D structure of type I GrCKIs was conservative, the same for all 16 of them (Figure S3). However, 3D structures of type II GrCKIs were variable: only some proteins showed similar structures (GrCKI17, GrCKI18, and GrCKI21; GrCKI24, GrCKI25, and GrCKI29). To obtain more insights into the diversity of motif compositions among GrCKI proteins, the conserved motifs in the Cterminal were further analyzed with the program MEME. As shown in Figure $2 d$, the conserved motifs $1-8$ were identified. Based on the motif composition, GrCKI proteins were divided into five groups (A-E); type I GrCKI proteins were divided into groups A to C; type II GrCKI proteins were classified into groups D and E. Most of the type I GrCKI proteins within the same group shared similar motif compositions while high divergence was observed among different groups, implying that the type I GrCKI members within the same group may perform similar functions and that some motifs may play an important role in the specific functions of the group. For example, all the type I GrCKI except GrCKI5 in Group A possessed motifs 1, 2, 3, 4, and 5, while all members in Group $C$ contained motifs 1 and 4 (Figure 2d). GrCKI22 and GrCKI23, which were type II GrCKI proteins, had short sequences and thus showed no motif. Except GrCKI20 and GrCKI29 which contained seven motifs, the vast majority of type II GrCKI proteins presented similar eight motifs composition. Generally, the consistency of motif compositions of GrCKI proteins with the phylogenetic groups further supported the close evolutionary relationships among GrCKIs, as well as the reliability of our phylogenetic analysis. To get a better understanding of the diversification of type I and type II GrCKI genes in G. raimondii, the exon/intron organization was analyzed. As expected, most 
GrCKIgenes within the same group showed very similar exon/intron distribution patterns in terms of exon length and intron number (Figure S4). For example, most type I GrCKI genes in groups A, B, and C had thirteen or fourteen exons of similar length, whereas members of type II GrCKI genes within Group D and E contained sixteen or seventeen exons, except for GrCKI22 (Gorai.013G175600.1) "GrCKI23 (Gorai.006G042700.1) and GrCKI29 (Gorai.007G343500.1),, which possessed one, one, and fourteen exons, respectively. Thus, similarly to the exon/intron organization, members belonging to the same group also showed similar motif composition, indicating their functional similarities. And the diverse evolutionary patterns in exon numbers of the $C K I$ genes may hint at their functional diversifications in gene expression. These results further supported the classification between type I and type II GrCKI genes.

\section{The CKI Gene Family mainly Expanded through Genome Duplication}

To examine the evolutionary history of the $C K I$ genes, we firstly carried out phylogenetic analysis between the eudicots (G. raimondii and Arabidopsis) and monocot (rice) (Figure S5). Clearly, the CKI genes from eudicots (G. raimondii and Arabidopsis) and monocot (rice) were present in all subgroups (Table S1), indicating that the appearance of most $C K I$ genes in plants precedes the divergence between monocots/eudicots. The phylogenetic analysis also showed that the $C K /$ members from different plant species were not evenly distributed in the subgroups. Some CKI genes in Arabidopsis have two or more counterparts in G. raimondii. For example, Group D contained five G. raimondii CKIs but only one Arabidopsis member; Group E contained ten G. raimondii CKIs but there were only three Arabidopsis CKI genes. The findings may indicate that the CKIs from different plant species underwent differential expansion, though the mechanism is still not understood. Plant evolution is characterized by genome duplication events, which in turn resulted in the expansion of many gene families. Four duplication events have been detected in cotton from the ancient angiosperms development period to the stage of tetraploid cotton species: an ancient whole genome duplication (WGD) very early in angiosperm evolution, one triplication event, the recent WGD event specific for cotton, and the tetraploid event $[22,25,28]$. Previous reports calculated the absolute dates for the large-scale gene duplications using the assumed clock-like rates of synonymous substitution of $2.6 \times 1.0^{-9}$ substitutions/synonymous site/year [29]. Hence, based on Ks values, we calculated the divergence time of homologous $C K I$ genes in $G$. raimondii. The result was compared with the estimated time of WGD, which suggests that there were three CKI genes for type I and two for type II. During the genome triplication event shared by flowering plants, one of type II CKIs was duplicated into three copies (Figure 3a). After the subsequent ancient triplication event, the three type I $C K I$ genes and one of the type II genes in Group D tripled. Interesting, only group $A$ of the type I $C K I$ gene showed the triploidization: the rest of the $C K I$ only duplicated. It is also possible that they all underwent triploidization but then lost some copies, though it is difficult to determine. However, in all these events type II CKI genes in Group E did not even undergo duplication (Figure 3a). G. raimondii and Theobroma cacao originated from a common ancestor 18-58 million years ago [23]. Because of this, the gene numbers of type I or II CKI should match those of a common ancestor of G. raimondii and T. cacao. The CKI gene numbers in T. cacao were consistent with the speculation (Figure 3b and 3c; Table S1). Also, each $C K I$ gene in T. cacao had one or more counterparts in G. raimondii. Type I and II CKI genes 
conformed to the rule. After the species divergence, the two types both underwent the duplication events. Furthermore, because of the tetraploid event, one type II CKI gene in group E duplicated and resulted in two different genes, Gorai.006G042700.1 and Gorai.013G175600.1. In short, the CKI subgroups showed various degrees and patterns of duplications, probably associated with many known WGD events which greatly expanded the number of genes in seed plants.

\section{Expression Profiles of CKI Genes in Different Tissues from G. hirsutum}

Several findings suggested that $C K I$ genes are involved in plant development $[16,17,20]$. To further associate the biological functions of $C K I$ genes with specific developmental processes in cotton, the expression profiles in different organs/tissues (including roots, stems, leaves, petals, anthers, and 5 DPA [days post anthesis] ovules) were examined by quantitative RT-PCR (qRT-PCR). Because of the high sequence similarity between GhCKIA and GhCKID CDNAs, we designed one common primer pair for analyzing $C K I A / D$ gene expression. After the specificity for each primer pair was verified, suitable qRT-PCR primer pairs for 44 (26 type I CKI genes and 18 type II CKI genes) of the $61 C K /$ genes (33 type I CKI genes and 28 type II CKI genes) were obtained (Table S2). As shown in Figure S6, the majority of the type I and type II $C K /$ genes exhibited different tissue expression. GhCKI2A/D, GhCKI3A/D, GhCKI8A/D, GhCKI10A/D, GhCKI11A/D, GhCKI14A/D, GhCKI15A/D, GhCKI18A/D, GhCKI20A/D, and GhCKI27A/D were constitutively expressed in every tested tissue, implying that these genes may play regulatory roles at multiple developmental stages. In addition, some genes were highly expressed in specific tissues only. For example, the expression levels of GhCKI1A/D, GhCKI5A/D, GhCKI9A/D, GhCKI12A/D, GhCKI13A/D, GhCKI19A/D, GhCKI26A/D,GhCKI28A/D, GhCKI29A/D, GhCKI30A/D, and GhCKI31A/D were very high in anthers. The transcripts of some other genes, such as GhCKI4A/D, GhCKI14A/D, GhCKI2OA/D, and GhCKI27A/D, were preferentially expressed in leaves. These results provide additional insight into their roles during different growth and development processes in cotton.

\section{CKI Genes Respond to High Temperature during Cotton Anther Development Process}

CKI genes exhibited the highest expression in cotton anthers, except for GhCKI14A/D and GhCKI27A/D (Figure S6). Our previous studies showed that one member of the CKI gene family, GhCKI (Gh_A07G0121/GhCKI11A) was induced in $\mathrm{H} 05$ (the high temperature (HT)-sensitive line) anthers, but not in 84021 (the HT-tolerant line) anthers under HT condition [20]. Genome-wide analyses of G. hirsutum CKI genes in response to $\mathrm{HT}$ during anthers development may lay a foundation for further understanding the mechanisms involved in HT tolerance or HT sensitivity. In the present study, a heat-map representing expression profiles was produced using the transcriptomic data which contained the three different anther development stages (TS, tetrad stage; TDS, tapetal degradation stage; ADS, anther dehiscence stage) of 84021 and $\mathrm{H} 05$ under HT and NT [30]. It was observed that 34 of $61 \mathrm{GhCKI}$ genes (19 from type I and 15 from type II) were differently expressed in 84021 and H05 under HT and NT, even after filtering with an absolute threshold $\log _{2}$ ratio $\geq 1$ (Figure $4 a$ ). We found that most genes were more expressed in H05 after HT exposure, such as type I genes (GhCKI10 and GhCKI11)and type II genes (GhCKI2O and GhCKI27)Figure 4a). To verify the result, the qRT-PCR experiments were also performed (Figure 4b), but no 
obvious differences were observed after $\mathrm{HT}$ treatment in anthers, consistently with the RNA-seq data. These results indicated that HT influenced the expression of both type I and type II GhCKI genes during anther development.

\section{Circadian Rhythm and Light Signal Regulation of GhCKI Gene Expression}

To determine whether the expression of cotton $C K I$ genes is regulated by photoperiod (circadian clock), the transcription level of $G$. hirsutum $C K I$ genes under different diurnal conditions were investigated. Thirty-six $G$. hirsutum $C K I$ genes were expressed at a sufficient level to evaluate their circadian regulation (Figure 5). Twelve type I genes (GhCKI1A/D, GhCKI2A/D, GhCKI3A/D, GhCKI8A/D, GhCKI13A/D, and GhCKI14A/D) and ten type II genes (GhCKI19A/D, GhCKI20A/D, GhCKI27A/D, GhCKI28A/D, and GhCKI30A/D) showed a high expression peak at 12:00 under long-day (LD) conditions. The expression peaks of eight type I genes (GhCKI4A/D, GhCKI11A/D, GhCKI12A/D, and GhCKI15A/D) and six type II genes (GhCKI18A/D, GhCKI26A/D, and GhCKI31A/D) were at 16:00 under long-day (LD) conditions. Under short-day (SD) conditions, all the $36 \mathrm{CKI}$ genes showed a high expression peak at 8:00, and the expression of GhCKI genes increased gradually in the dark and decreased in the light. However, the expression of the $36 \mathrm{GhCKI}$ genes showed different results under LD conditions, the expression was higher in the light than in the dark. These results identified a set of clock-regulated GhCKI genes showing different phases of expression and provided additional insight to understand the underlying mechanisms of modulation in light signaling.

To further investigate whether CKIs are involved in light signaling, the expression of $G$. raimondii (Figure S7) and G. hirsutum (Figure 6) CKI genes in cotyledon under light and dark conditions was examined by qRT-PCR. The expression of most $C K I$ genes both in $G$. raimondii and $G$. hirsutum was up-regulated under light, except for GhCKI19A/D (Figure 6), GrCKI6, GrCKI14, GrCKI25, and GrCKI26 (Figure S7). However, there was only a slight difference between the two types of $C K I$ genes. The results indicated both type I and type II might be involved in plant light signal.

\section{Discussion}

\section{Structural Characteristics of G. raimondii CKI genes}

In animals, certain characteristics of $C K /$ that certainly influence its activity have been identified at the protein level: structure-related regulation, subcellular localization, interaction with other proteins, and posttranslational modifications [31]. As a member of the superfamily of serine/threonine-specific kinases, the function of phosphorylation is a priority to focus on. However, the characteristics of phosphorylation and sequences of plant $C K /$ genes were not systematically analyzed in this study Instead, we systematically identified CKI genes in the eudicots (Arabidopsis thaliana, Theobroma cacao, G. raimondii, G. arboreum, and G. hirsutum acc. TM-1) and in one monocot (Oryza sativa) (Figure 1, Figure 3, and Figure S5). Based on sequence comparison and phylogenetic analysis, plant $C K I$ genes were first divided into two groups, namely type I and type II CKI genes (Figure 1, Figure S1, and Figure S5). Motif compositions, 3D protein 
structure, and exon/intron distribution patterns in terms of exon number in G. raimondii agreed with our hypothesis (Figure 2, Figure S3 and Figure S4).

Regarding the functional characteristics of the $\mathrm{N}$-terminal and conserved $\mathrm{C}$-terminal regions, previous reports in mammals showed that CKI presents a $\beta$-sheets $\mathrm{N}$-terminal lobe and mainly a a-helical Cterminal lobe, which are connected by a hinge region forming a catalytic cleft for substrate and ATP binding [32-33]. Within the C-terminal region, a specific phosphate moiety binding motif has been identified allowing the recognition of phosphorylated protein substrates, which is believed to be involved in $\mathrm{CKI}$ regulatory interactions. These reports showed that the $\mathrm{N}$-terminal and $\mathrm{C}$-terminal lobes play an important role in substrate phosphorylation. In this study, type I CKI proteins resulted highly conserved within their kinase domains, but significantly differing in the length and primary structure of their $\mathrm{N}$ terminal and C-terminal domains (Figure 2a), which is consistent with previous reports [3, 4, 26, 31, 34]. Interestingly, contrary to type I, type II CKI proteins also presented conserved kinase domains and possessed variable $\mathrm{N}$-terminal and conserved $\mathrm{C}$-terminal regions (Figure 2b). Furthermore, the 3D structures of type I CKI proteins were always identical, while type II were inconsistent (Figure S3). Based on the characteristic of plant $C K I$ genes, we hypothesis the type I and type II $C K I$ genes possess different functions on account of the difference in structures, especially regarding the function of phosphorylation. Functional studies will be needed in the future to further explore this difference.

\section{Evolutionary Expansion of the G. raimondii CKI Gene Family}

The evolution of Gossypium CKI genes was characterized by a history of multiple gene duplications at different stages as in the four duplication events (an ancient angiosperm WGD event, one triplication event, a specific and recent cotton WGD event, and the tetraploid event) $[22,25,28]$. The phylogeny obtained in this study suggested that Gossypium CKI genes may be traced back to 250 million years ago, before the ancestral angiosperm WGD event (Figure 3a). At this node, duplication created five ancestral genes (three type I CKI genes and two type II CKI genes) (Figure 3a). Thereafter, with the divergence of angiosperms, independent duplications occurred in different lineages (such as eudicots [G. raimondii and Arabidopsis] and monocots [rice]), generating specific duplication events. The five ancestral genes duplicated in the four events to reach the current $C K I$ gene numbers. However, all the 31 members of the $C K I$ gene family in $G$. raimondii did not equally derived from the five ancestral genes. Two of the five ancestral genes (Group A and Group E) duplicated vigorously, creating 19 members of the CKI gene family in $G$. raimondii. At another key node, the rapid amplification of $C K /$ genes was due to a wholegenome duplication (WGD) event in the Gossypium genus after its separation from T. cacao (Figure $3 b$ ) [23]. In addition, the $C K I$ members from eudicots (G. raimondii and Arabidopsis) and monocot (rice) were not equally distributed among the subgroups (Figure S5), which indicated that the CKI genes from different plant species went through differential expansion. Therefore, we speculated that the origin of the $C K I$ genes was very ancient and the expansion might have occurred in different plant species and arose from independent duplications. Besides, the gene families which possess an ancient evolutionary history have important functions, such as MADS-box genes[35], Auxin response factors [36], or ASYMMETRIC LEAVES2-LIKE/ LOB-DOMAIN transcription factors[37]. Thus, we speculate that CKI genes 
may play important roles in plant development and be involved in very diverse biological roles to adapted to environmental stress.

\section{Expression Patterns of the CKI Genes Suggest Functional Diversification}

To date, although the functions of only one $C K I$ gene have been characterized in tetraploid cotton [20], no systematic functional analysis of expression patterns for different groups of the tetraploid cotton $C K I$ gene family was done. In this study, we demonstrated that $C K I$ genes displayed expression divergence in roots, leaves, and anthers (Figure S6). For instance, GhCKI2A/D, GhCKI3A/D, GhCKI8A/D, GhCKI1OA/D, GhCKI11A/D, GhCKI15A/D, and GhCKI18A/D were constitutively expressed in every tested tissue (such as roots), implying that these genes may play regulatory roles at multiple development stages. In Arabidopsis, AtCKL2 and AtCKL3 were required for ABA regulation of seed germination, root growth, and gene expression $[16,17]$. In rice, OsCKI1 deficiency resulted in shorter primary roots and fewer lateral and adventitious roots [2]. Similar expression patterns suggest that these preferentially or specifically expressed G. hirsutum $C K I$ genes might play important roles in root formation and development. Among these 61 identified $C K I$ genes, GhCKI (namely GhCKI11A) is the only one that was speculated to regulate tapetal programmed cell death and anther dehiscence in cotton [20]. Under HT condition, AtCKL2 and AtCKL 7 were expressed in the tapetum, in anther microspores at stages 9-12, and in anther pollen grains at stages 13-14, which imply AtCKL2 and AtCKL7 may be key regulators of tapetal development under HT [38]. Apart from GhCKI11A (formerly GhCKI), the GhCKI1A/D, GhCKIIAA/D,GhCKI9A/D, GhCKI12A/D, GhCKI13A/D, GhCKI19A/D,GhCKI26A/D, GhCKI28A/D, GhCKI29A/D, GhCKI30A/D, and GhCKI31A/D genes were exclusively expressed in anther. This finding suggested that $C K I$ genes were components of a complex transcriptional network regulating anther development.

Previous studies had showed that HT stress causes premature programmed cell of the tapetum, resulting in male sterility and catastrophic loss of crop production [30, 39-41]. However, the mechanism underlying successful male reproductive development under $\mathrm{HT}$ remains largely unknown. Except for the GhCKI11A (formerly GhCKI) gene, which was reported to regulate tapetum development under HT [20], no other $C K I$ genes have demonstrated to participate in the regulation of anther development. This study, using the transcriptomic data of cotton anther in response to $\mathrm{HT}$, found that $34 \mathrm{CKI}$ genes changed the expression at different anther development stages under HT (Figure 4). These are now further $\mathrm{CKI}$ genes that participate in regulating stamen development under $\mathrm{HT}$ and that will be employed in future works.

Circadian clocks are molecular timekeepers. Many plants use photoperiod (circadian clock) information to prepare for daily environmental changes and increase their fitness in changing environments [42]. The circadian clocks share similar network architecture of feedback loops that form by transcriptional and post-translational regulation among the clock components $[43,44]$. Phosphorylation is a common posttranslational modification and is an integral part of circadian regulation [44]. Another function of $C K I$ is to take a series of biological process via phosphorylating various substrates [3]. In rice, Early flowering 1 (EL1)/ Heading date 16 (Hd16), a CKI protein, regulated the rice flowering pathway by enhancing the photoperiod response caused by the phosphorylation of DELLA protein SLR1 and Ghd7 [13, 14]. In 
Arabidopsis, both $C K 1.3$ and $C K 1.4$ showed a high expression peak before dark under LD conditions, which indicated that the expression of $C K 1.3$ and $C K 1.4$ was strictly regulated by a circadian rhythm; overexpression of either $C K 1.3$ or $C K 1.4$ delayed flowering under LD conditions [18]. However, in cotton, it is not clear that the systematic function of the tetraploid cotton $C K /$ gene family is involved in photoperiod (circadian clock). In our present study, the expression of $C K I$ genes is circadian. Under longday (LD) conditions, the expression in the light is higher than in the dark. Under short-day (SD) conditions, the expression of all the $36 \mathrm{CK} /$ genes showed a high expression in dark. (Figure 5). The results indicated that the expression of $C K /$ was strictly regulated by a circadian rhythm. According to these evidences, we propose that at least some $C K I$ genes are components of a diurnal rhythm complex network. The functions of these GhCKI genes in regulating the circadian clock on the diurnal rhythms will be further characterized in future works.

Plant reception of light signal and its subsequent reaction is important for both growth and development. In Arabidopsis, CK1 genes are involved in the light signaling pathway mainly through phosphorylation; casein kinase 1 proteins CK1.3 and CK1.4 phosphorylate CRYPTOCHROME 2 (CRY2) which is the bluelight receptor, to regulate blue light signaling [18]. Our results showed that the expression of most type I and type II CKI genes was upregulated under light conditions compared to dark (Figure 6, Figure S7). We thus believe that both type I and type II CKI gene are involved in the response to light signals. But we do not know how these genes respond to light signals in cotton, and whether they participate in light signals by phosphorylating photoreceptors CRY2 or light signal components, including HY5, HF5, HFR1, COP1, and PIF1, which in Arabidopsis are phosphorylated by casein kinase 2 proteins [45]. We also do not know whether the pathways and capabilities of these two types of genes are the same.

\section{Conclusion}

Our study offers a promising landscape to unravel the underlying structural characteristics and evolutionary expansion of $C K I$ genes and further elucidate their expression patterns in different tissues and various conditions; this is crucial to better understand their characteristics and to elucidate their precise functions in regulating various facets of plant growth and development.

\section{Methods}

Database search and identification of CKI genes

The genomic database of three cotton species G. raimondii, G. arboreum and G. hirsutum acc. TM-1 were downloaded from $h t t p s: / / W w w$. cottongen.org/. The protein database of $A$. thaliana, $O$. sativa and $T$.

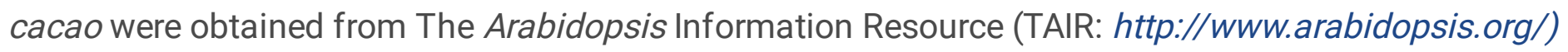
and http://www.phytozome.net/, respectively. BLAST searches were performed using $13 \mathrm{CKL}$ genes within the Arabidopsis casein kinase 1-likegene family and heading date 16 (Hd16) encoding a casein kinase I protein as queries. The candidate CKI proteins were further aligned to remove redundant 
sequences. Subsequently, the four specific fragments (LLGPSLEDLF, HIPXR, EXSRRDD, and LPWQGLKA) were used to further confirm the presence of the CKI protein sequences.

Gene structure and phylogenetic analysis

Sequence alignments were generated with CLUSTALX [46], and the alignments among CKIs were adjusted before the tree was constructed. The online Gene Structure Display Server 2.0 [47] (http://gsds.cbi.pku.edu.cn/) was used to identify the exon/intron organization. G. raimondii CKI protein sequences were submitted to online MEME (Multiple EM for Motif Elicitation) program [48] (http://memesuite.org/tools/meme) to identify conserved protein motifs. The 3D structure of GrCKI proteins was predicted by SWISS-MODEL (https://swissmodel.expasy.org) [27]. Phylogenetic trees were constructed by the Maximum likelihood method in MEGA 6 [49].

\section{Plant materials, growth conditions and stress treatments}

Four cotton accessions used in this experiment are provided by Huazhong Agricultural University. For the expression profiles in different organs/tissues, various samples of G. hirsutum cv. YZ1 were extracted from roots, stems, leaves, petal, anther, and ovules excised carefully from bolls five DPA. To analysis the expression patterns of Gossypium hirsutum CKI genes at different anther developmental stages under NT and HT conditions, two cotton (Gossypium hirsutum) lines with obvious differences in performance under $\mathrm{HT}$ were employed in this study: 84021 , which is tolerant to $\mathrm{HT}$, and $\mathrm{H05}$, which is sensitive to $\mathrm{HT}$ [30]. The plants were grown in a greenhouse at $28^{\circ} \mathrm{C}$ to $35^{\circ} \mathrm{C} / 20^{\circ} \mathrm{C}$ to $28^{\circ} \mathrm{C}$ day/night as a normal condition. During HT treatment, the plants were cultivated at $35^{\circ} \mathrm{C}$ to $39^{\circ} \mathrm{C} / 29^{\circ} \mathrm{C}$ to $31^{\circ} \mathrm{C}$ day/night in a greenhouse. When the plants were treated with $\mathrm{HT}$ for $7 \mathrm{~d}$, buds of different lengths $(6-7,9-14$, and more than $24 \mathrm{~mm}$ ) were collected under HT and NT. The anthers were excised and immediately frozen in liquid nitrogen; they were then stored at $-80^{\circ} \mathrm{C}$ until use. The transcriptome profiles of $C K I$ genes were isolated from the RNA-seq data [30]. In order to analyze the diurnal regulation of $G$. hirsutum CKIs gene expression, G. hirsutum cv. YZ1 was grown under short-day conditions (8 h light/16 h dark) and long-day conditions ( $16 \mathrm{~h}$ light/ $8 \mathrm{~h}$ dark), respectively. The leaves of four leaves period cotton plants were harvested. We also collected cotyledons under light and dark conditions, that from $G$. raimondii and $G$. hirsutum cv.YZ1 respectively.

qRT-PCR

Various plant samples were collected and immediately frozen in liquid nitrogen and stored at $-80^{\circ} \mathrm{C}$. total RNA was isolated from the collected cotton tissues using previously published methods [50]. First-strand cDNA was generated from $3 \mu \mathrm{g}$ total RNA using the M-MLV reverse transcriptase (Invitrogen). The cDNA was used as a template for qRT-PCR. The qRT-PCR reactions were performed using the 7500 Real-Time PCR System (Applied Biosystems). The primers used in this study were listed in Table S2, Table S3.

\section{Abbreviations}


CKI, Casein kinase I; ABA, abscisic acid; BR, brassinolide; EL1, Early flowering 1; Hd16, Heading data 16; PCD: programmed cell death; MLK3: Mut9-like kinases 3; CKL, Casein Kinase 1-like; Gr, G. raimondii; Gh, G. hirsutum; WGD, whole genome duplication; DPA, days post anthesis; HT, high temperature; NT, normal temperature; TS, tetrad stage; TDS, tapetal degradation stage; ADS, anther dehiscence stage; LD, long-day; $\mathrm{SD}$, short-day;

\section{Declarations}

\section{Ethics approval and consent to participate}

Not applicable

\section{Consent for publication}

Not applicable

\section{Competing interest}

The authors declare no conflicts of interest.

\section{Acknowledgments}

Not applicable

\section{Author contributions}

Y.L. carried out the experiment with Y.L. and wrote the main manuscript text, Y.C. and M.W. analysed the data, L.M, X.Z and L.Z. designed and supervised the research and revised the manuscript. All authors reviewed the manuscript.

\section{Funding}

This work was supported by the National Key Research and Development Program of China (2016YFD0101402, 2018YFD0100403).

\section{Availability of data and materials}

The data that support the results are included within the article and its additional files. Other relevant materials are available from the corresponding authors on reasonable request.

\section{References}

1. Tuazon PT, Traugh J. A Casein kinase I and II-multipotential serine protein kinases: structure, function, and regulation. Advances in Second Messenger and Phosphoprotein Research. 1991; 23: 123-164. 
2. Liu W, Xu ZH, Luo D, Xue HW. Roles of OsCKI1, a rice casein kinase I, in root development and plant hormone sensitivity. The Plant Journal. 2003; 36(2): 189-202.

3. Knippschild U, Gocht A, Wolff S, Huber N, Löhler J, Stöter M. The casein kinase 1 family: participation in multiple cellular processes in eukaryotes. Cellular Signalling. 2005; 17(6): 675-689.

4. Graves PR, Haas DW, Hagedorn CH, DePaoli-Roach AA, Roach PJ. Molecular cloning, expression, and characterization of a 49-kilodalton casein kinase I isoform from rat testis. The Journal of Biological Chemistry. 1993; 268(9): 6394-6401.

5. Babu P, Deschenes RJ, Robinson LC Akr1p-dependent palmitoylation of Yck2p yeast casein kinase 1 is necessary and sufficient for plasma membrane targeting. The Journal of Biological Chemistry. 2004; 279(26): 27138-27147.

6. DeMaggio AJ, Lindberg RA, Hunter T, Hoekstra MF. The budding yeast HRR25 gene product is a casein kinase I isoform. Proceedings of the National Academy of Sciences of the United States of America. 1992; 89 (15): 7008-7012.

7. Petronczki M, Matos J, Mori S, Gregan J, Bogdanova A, Schwickart M, Mechtler K, Shirahige K, Zachariae W, Nasmyth K. Monopolar attachment of sister kinetochores at meiosis I requires casein kinase 1. Cell. 2006; 126(6): 1049-1064.

8. Robinson LC, Menold MM, Garrett S, Culbertson MR. Casein kinase I-like protein kinases encoded by YCK1 and YCK2 are required for yeast morphogenesis. Molecular and cellular biology. 1993; 13(5): 2870-2881.

9. Liu C, Li Y, Semenov M, Han C, Baeg GH, Tan Y, Zhang Z, Lin X, He X. Control of beta-catenin phosphorylation/degradation by a dual-kinase mechanism. Cell. 2002; 108(6): 837-847.

10. Peters JM, McKay RM, McKay JP, Graff JM. Casein kinase I transduces Wnt signals. Nature. 1999; 401(6751): 345-350.

11. Price MA, Kalderon D. Proteolysis of the Hedgehog signaling effector Cubitus interruptus requires phosphorylation by Glycogen Synthase Kinase 3 and Casein Kinase 1. Cell. 2002; 108(6): 823-835.

12. Kang J, Wang Z. Mut9p-LIKE KINASE Family Members: New Roles of the Plant-Specific Casein Kinase I in Plant Growth and Development. International Journal of Molecular Sciences. 2020; 21(5): 1562.

13. Dai C, Xue HW. Rice early flowering1, a CKI, phosphorylates DELLA protein SLR1 to negatively regulate gibberellin signalling. The EMBO Journal. 2010; 29 (11): 1916-1927.

14. Hori K, Ogiso-Tanaka E, Matsubara K, Yamanouchi U, Ebana K, Yano M. Hd16, a gene for casein kinase $\mathrm{I}$, is involved in the control of rice flowering time by modulating the day-length response. The Plant Journal. 2013: 76(1): 36-46.

15. Lee JY, Taoka K, Yoo BC, Ben-Nissan G, Kim DJ, Lucas WJ. Plasmodesmal-associated protein kinase in tobacco and Arabidopsis recognizes a subset of non-cell-autonomous proteins. The Plant Cell. 2005; 17(10): 2817-2831.

16. Wang MK, Yu DS, Guo XH, Cui Y, Li XS, Zhang JH, Zhao LJ, Chang HP, Hu S, Zhang C, Liu XM. Casein kinase 1 -like 3 is required for abscisic acid regulation of seed germination, root growth, and gene 
expression in Arabidopsis. Afr J Biotechnol. 2010 10(61): 13219-13229.

17. Cui Y, Ye J, Guo X, Chang H, Yuan C, Wang Y. Arabidopsis casein kinase 1-like 2 involved in abscisic acid signal transduction pathways. Journal of Plant Interactions.2012; 9(1): 19-25.

18. Tan ST, Dai C, Liu HT, Xue HW. Arabidopsis casein kinase1 proteins CK1.3 and CK1.4 phosphorylate cryptochrome2 to regulate blue light signaling. The Plant Cell. 2013; 25(7): 2618-2632.

19. Kang J, Cui H, Jia S, Liu W, Yu R, Wu Z, Wang Z. Arabidopsis thaliana MLK3, a Plant-specific Casein Kinase 1, Negatively Regulates Flowering and Phosphorylates Histone H3 in Vitro. Genes. 2020; $11(3): 345$.

20. Min L, Zhu L, Tu L, Deng F, Yuan D, Zhang X. Cotton GhCKI disrupts normal male reproduction by delaying tapetum programmed cell death via inactivating starch synthase. The Plant Journal. 2013; 75 (5): 823-835.

21. Min L, Hu Q, Li Y, Xu J, Ma Y, Zhu L, Yang X, Zhang X. LEAFY COTYLEDON1-CASEIN KINASE I-TCP15PHYTOCHROME INTERACTING FACTOR4 Network Regulates Somatic Embryogenesis by Regulating Auxin Homeostasis. Plant Physiology. 2015; 169(4): 2805-2821.

22. Paterson AH, Wendel JF, Gundlach H, Guo H, Jenkins J, Jin D, Llewellyn D, Showmaker KC, Shu S, Udall J, Yoo MJ, Byers R, Chen W, Doron-Faigenboim. A, Duke MV, Gong L, Grimwood J, Grover C, Grupp K, Hu G, ... Schmutz J. Repeated polyploidization of Gossypium genomes and the evolution of spinnable cotton fibres. Nature. 2012; 492(7429): 423-427.

23. Li F, Fan G, Wang K, Sun F, Yuan Y, Song G, Li Q, Ma Z, Lu C, Zou C, Chen W, Liang X, Shang H, Liu W, Shi C, Xiao G, Gou C, Ye W, Xu X, Zhang X, ... Yu S. Genome sequence of the cultivated cotton Gossypium arboretum. Nature Genetics.2014; 46(6): 567-572.

24. Zhang T, Hu Y, Jiang W, Fang L, Guan X, Chen J, Zhang J, Saski CA, Scheffler BE, Stelly DM, HulseKemp AM, Wan Q, Liu B, Liu C, Wang S, Pan M, Wang Y, Wang D, Ye W, Chang L, ... Chen ZJ. Sequencing of allotetraploid cotton (Gossypium hirsutum L. acc. TM-1) provides a resource for fiber improvement. Nature Biotechnology. 2015; 33(5): 531-537.

25. Wendel JF. New World tetraploid cottons contain Old World cytoplasm. Proceedings of the National Academy of Sciences of the United States of America. 1989; 86 (11): 4132-4136.

26. Cheong JK, Virshup DM. Casein kinase 1: Complexity in the family. The International Journal of Biochemistry \& Cell Biology. 2011; 43(4): 465-469.

27. Waterhouse A, Bertoni M, Bienert S, Studer G, Tauriello G, Gumienny R, Heer FT, de Beer T, Rempfer C, Bordoli L, Lepore R, Schwede T. SWISS-MODEL: homology modelling of protein structures and complexes. Nucleic Acids Research. 2018; 46(W1): W296-W303.

28. Jiao Y, Wickett NJ, Ayyampalayam S, Chanderbali AS, Landherr L, Ralph PE, Tomsho LP, Hu Y, Liang H, Soltis PS, Soltis DE, Clifton SW, Schlarbaum SE, Schuster SC, Ma H, Leebens-Mack J, dePamphilis CW. Ancestral polyploidy in seed plants and angiosperms. Nature. 2011; 473(7345) 97-100.

29. Renny-Byfield S, Gong L, Gallagher JP, Wendel JF. Persistence of subgenomes in paleopolyploid cotton after 60 my of evolution. Molecular Biology and Evolution. 2015; 32(4): 1063-1071. 
30. Min L, Li Y, Hu Q, Zhu L, Gao W, Wu Y, Ding Y, Liu S, Yang X, Zhang X. Sugar and auxin signaling pathways respond to high-temperature stress during anther development as revealed by transcript profiling analysis in cotton. Plant Physiology. 2014; 164(3): 1293-1308.

31. Knippschild U, Krüger M, Richter J, Xu P, García-Reyes B, Peifer C, Halekotte J, Bakulev V, Bischof J. The CK1 Family: Contribution to Cellular Stress Response and Its Role in Carcinogenesis. Frontiers in Oncology.2014; 4: 96.

32. Xu RM, Carmel G, Sweet RM, Kuret J, Cheng X. Crystal structure of casein kinase-1, a phosphatedirected protein kinase. The EMBO Journal. 1995; 14(5): 1015-1023.

33. Longenecker KL, Roach PJ, Hurley TD. Three-dimensional structure of mammalian casein kinase I: molecular basis for phosphate recognition. Journal of Molecular Biology. 1996; 257(3): 618-631.

34. Schittek B, Sinnberg T. Biological functions of casein kinase 1 isoforms and putative roles in tumorigenesis. Molecular Cancer. 2014; 13: 231.

35. Soltis DE, Ma H, Frohlich MW, Soltis PS, Albert VA, Oppenheimer DG, Altman NS, dePamphilis C, Leebens-Mack J. The floral genome: an evolutionary history of gene duplication and shifting patterns of gene expression. Trends in Plant Science. 2007; 12(8): 358-367.

36. Finet C, Berne-Dedieu A, Scutt CP, Marlétaz F. Evolution of the ARF gene family in land plants: old domains, new tricks. Molecular Biology and Evolution. 2013; 30(1): 45-56.

37. Coudert Y, Dievart A, Droc G, Gantet P. ASL/LBD phylogeny suggests that genetic mechanisms of root initiation downstream of auxin are distinct in lycophytes and euphyllophytes. Molecular Biology and Evolution. 2013; 30(3) 569-572.

38. Li YY, Min L, Zhang L, Hu Q, Wu Y, Li J, Xie S, Ma Y, Zhang X, Zhu L. Promoters of Arabidopsis Casein kinase I-like 2 and 7 confer specific high-temperature response in anther. Plant Molecular Biology. 2018; 98 (1-2): 33-49.

39. Ahuja I, de Vos RC, Bones AM, Hall RD. Plant molecular stress responses face climate change. Trends in Plant Science. 2010; 15(12) 664-674.

40. Abiko M, Akibayashi K, Sakata T, Kimura M, Kihara M, Itoh K. High-temperature induction of male sterility during barley (hordeum vulgarel.) anther development is mediated by transcriptional inhibition. Sexual Plant Reproduction. 2005; 18(2): 91-100.

41. Yu J, Han J, Kim YJ, Song M, Yang Z, He Y, Fu R, Luo Z, Hu J, Liang W, Zhang D. Two rice receptor-like kinases maintain male fertility under changing temperatures. Proceedings of the National Academy of Sciences of the United States of America. 2017; 114(46): 12327-12332.

42. Blümel $\mathrm{M}$, Dally $\mathrm{N}$, Jung $\mathrm{C}$. Flowering time regulation in crops-what did we learn from Arabidopsis?. Current Opinion in Biotechnology. 2015; 32: 121-129.

43. Doherty CJ, Kay SA. Circadian control of global gene expression patterns. Annual Review of Genetics. 2010; 44: 419-444.

44. Kusakina J, Dodd AN. Phosphorylation in the plant circadian system. Trends in Plant Science. 2012; 17(10): 575-583. 
45. Mulekar JJ, Huq E. Expanding roles of protein kinase CK2 in regulating plant growth and development. Journal of Experimental Botany. 2014; 65(11): 2883-2893.

46. Thompson JD, Gibson TJ, Higgins DG. Multiple sequence alignment using ClustalW and ClustalX. Current Protocols in Bioinformatics. 2002; 2.

47. Hu B, Jin J, Guo AY, Zhang H, Luo J, Gao G. GSDS 2.0: an upgraded gene feature visualization server. Bioinformatics. 2015; 31(8): 1296-1297.

48. Bailey TL, Williams N, Misleh C, Li WW. MEME: discovering and analyzing DNA and protein sequence motifs. Nucleic Acids Research. 2006; 34: W369-W373.

49. Tamura K, Stecher G, Peterson D, Filipski A, Kumar S. MEGA6: Molecular Evolutionary Genetics Analysis version 6.0, Molecular Biology and Evolution. 2013; 30(12): 2725-2729.

50. Deng F, Tu L, Tan J, Li Y, Nie Y, Zhang X. GbPDF1 is involved in cotton fiber initiation via the core ciselement HDZIP2ATATHB2. Plant Physiology. 2012; 158(2): 890-904.

\section{Tables}

Due to technical limitations, Table 1 is provided in the Supplementary Files section.

\section{Figures}




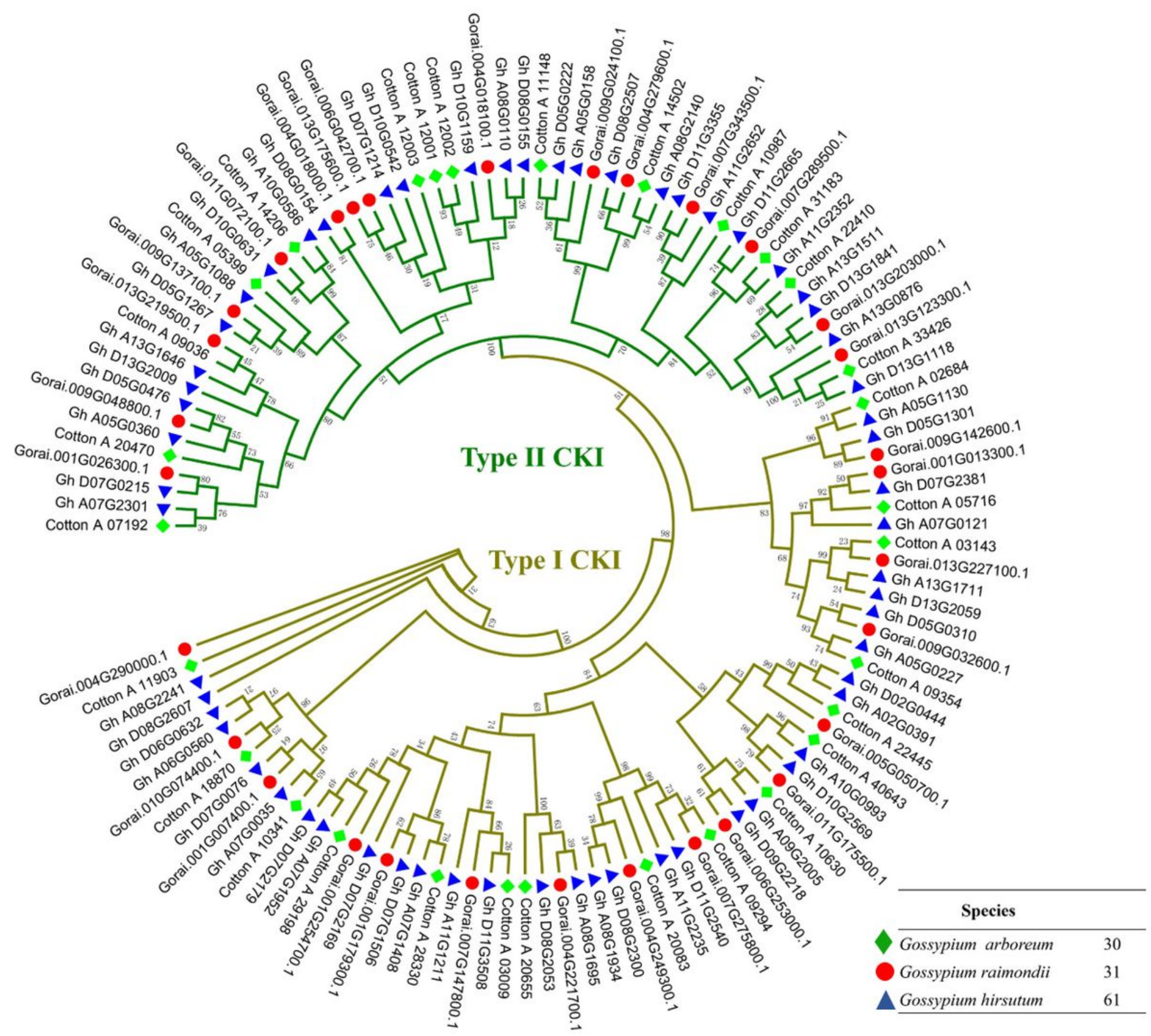

\section{Figure 1}

Phylogenetic tree of the Casein Kinase I (CKI) in Gossypium spp. The phylogenetic tree was constructed using 122 cotton CKI protein sequences from G. hirsutum (61), G. arboreum (30) and G. raimondii (31) with the Maximum likelihood method in MEGA 6. The three different symbols represent the three cotton species: green for $\mathrm{G}$. arboretum, red for $\mathrm{G}$. raimondii, and blue for $\mathrm{G}$. hirsutum. The GenelDs of CKI genes from G. hirsutum, G. arboreum, and G. raimondii were listed in Table 1. 
(a)

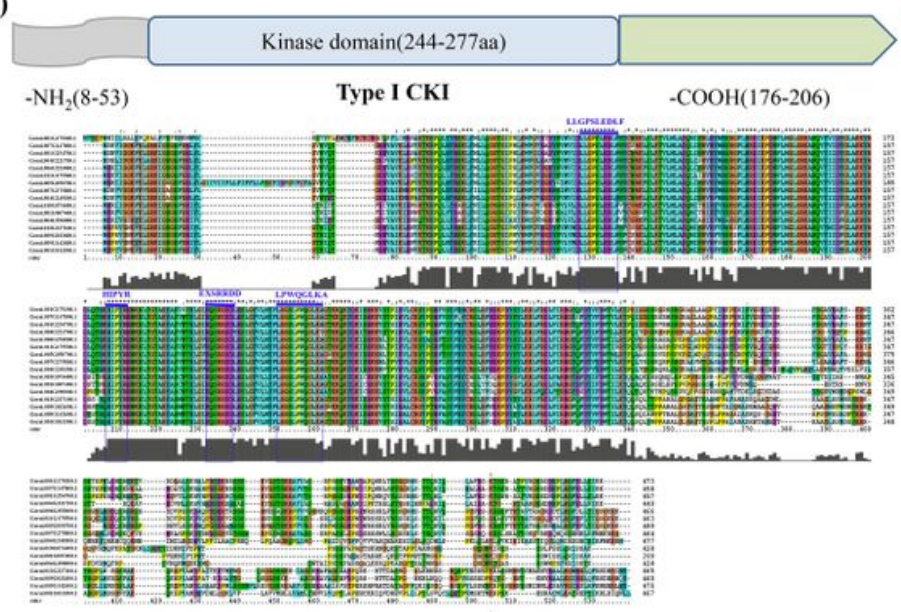

(c)
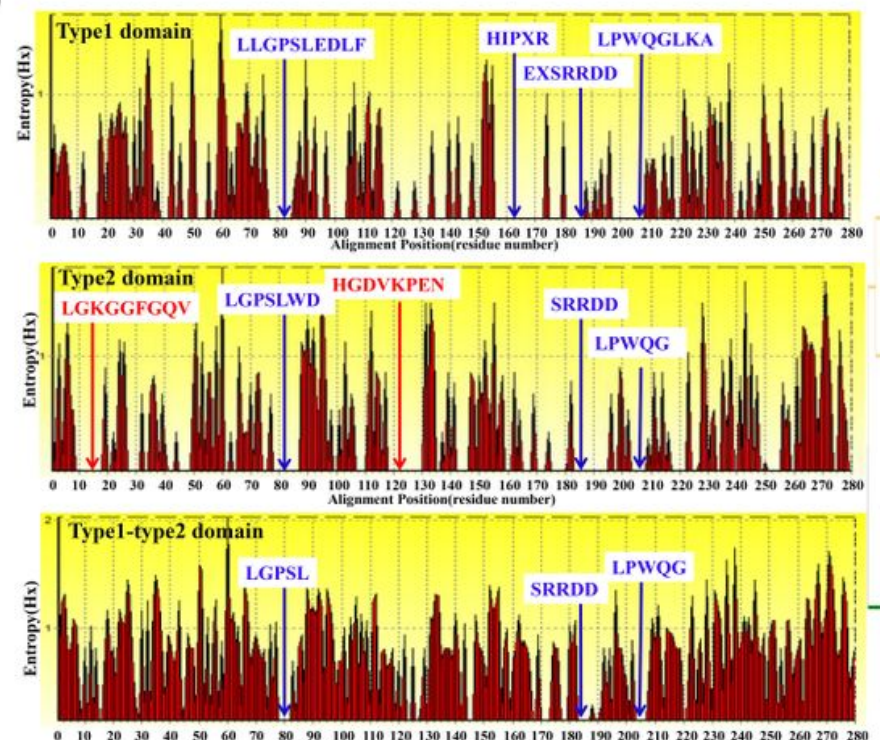

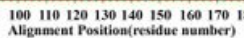

(b)
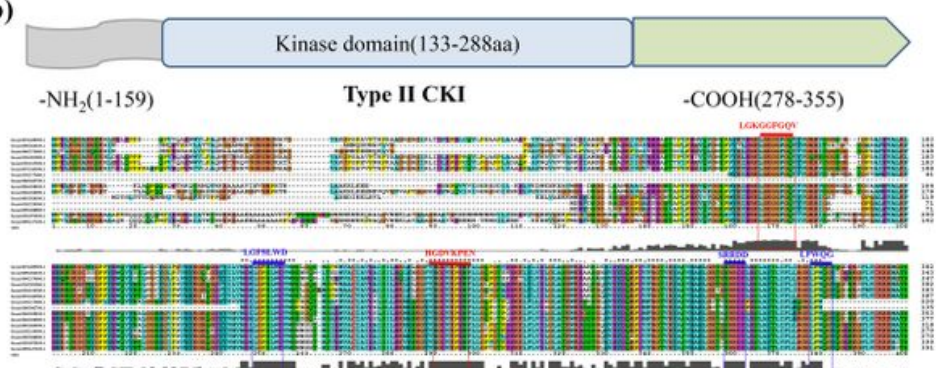

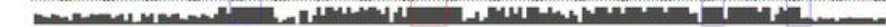

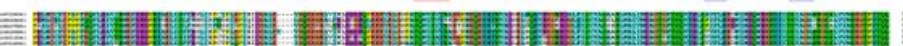

a

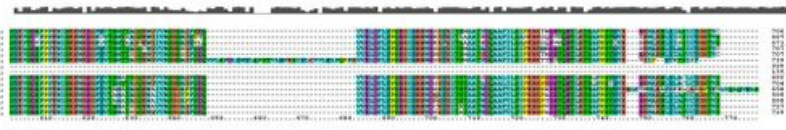

(d)

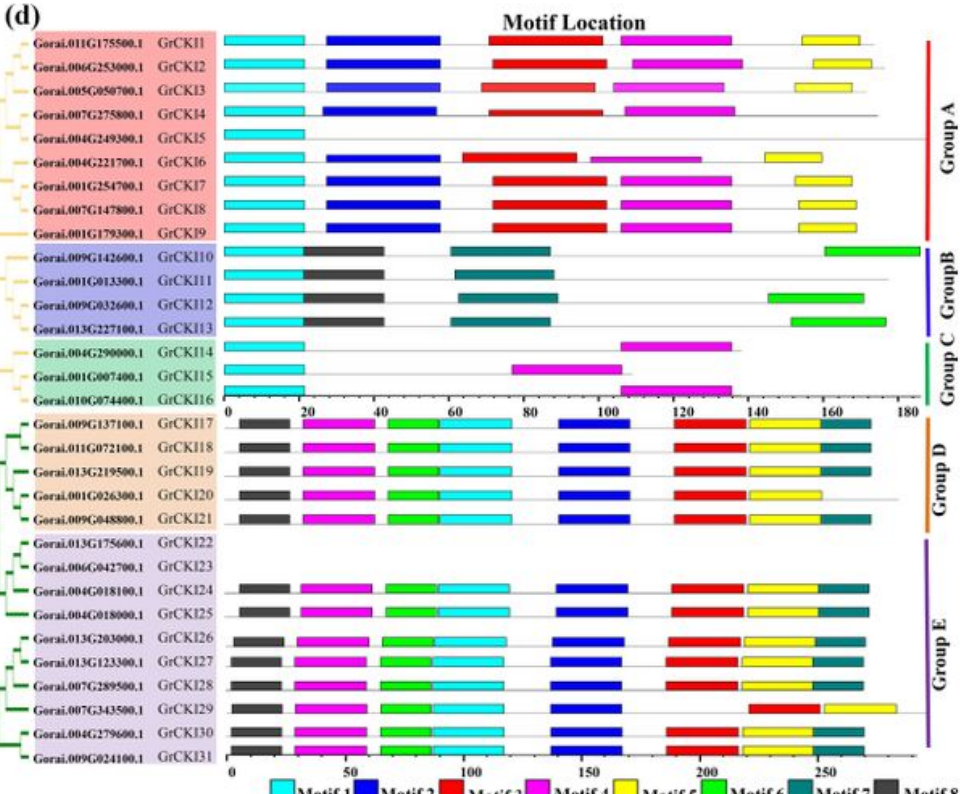

Figure 2

Gene structure and protein motif of the Casein Kinase I (CKI) in G. raimondii. (a) and (b) Multiple sequence alignments of type I and type II GrCKI proteins, respectively, in G. raimondii using ClustalX (c) The specific fragments exist in type I and type II GrCKI proteins. The red font indicates the specific fragments from type II GrCKI proteins. (d) Motif composition of GrCKI proteins. Conserved motifs in the GrCKI proteins are indicated by colored boxes. The GenelDs of type I and type II GrCKI genes were listed in Table S1 
(a)
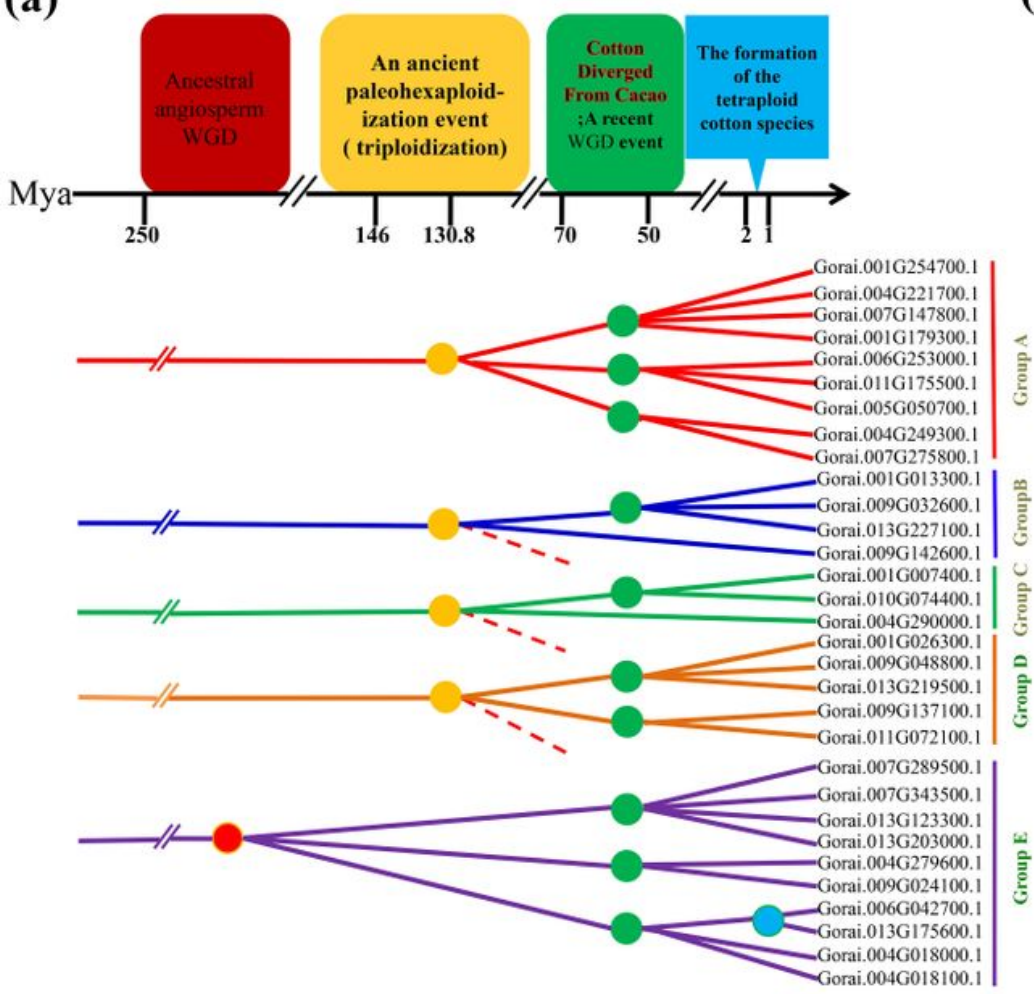

(c)

\begin{tabular}{cccccc}
\hline \multirow{2}{*}{ Species } & \multicolumn{3}{c}{ Type I CKI } & \multicolumn{2}{c}{ Type II CKI } \\
& Group A & Group B & Group C & Group D & Group E \\
\hline theobroma cacao & 3 & 2 & 2 & 2 & 3 \\
Gossypium raimondii & 9 & 4 & 3 & 5 & 10 \\
\hline
\end{tabular}

(b)
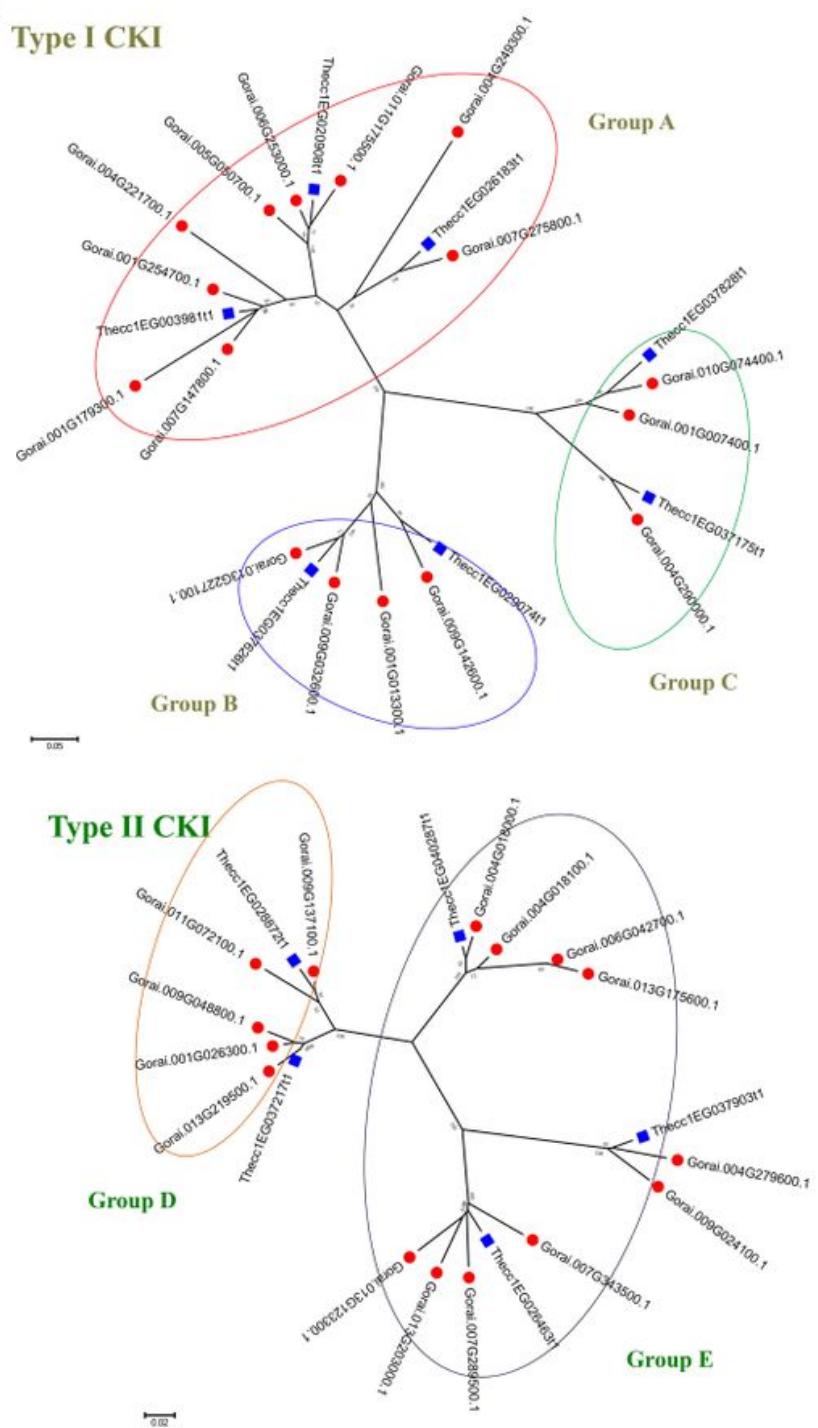

\section{Figure 3}

Evolutionary expansion of the G. raimondii CKI gene family and phylogenetic analysis of CKIs in G. raimondii and T. cacao. (a) The putative evolutionary history of the GrCKI genes. The four colored boxes represent the four duplication events. (b) Phylogenetic analysis of type I and type II CKI genes in G. raimondii and T. cacao, respectively. (c) Number of CKI genes in G. raimondii and T. cacao in different groups. The Gene IDs of type I and type II CKI genes from G. raimondii and T. cacao were listed in Table S1. 
(a)

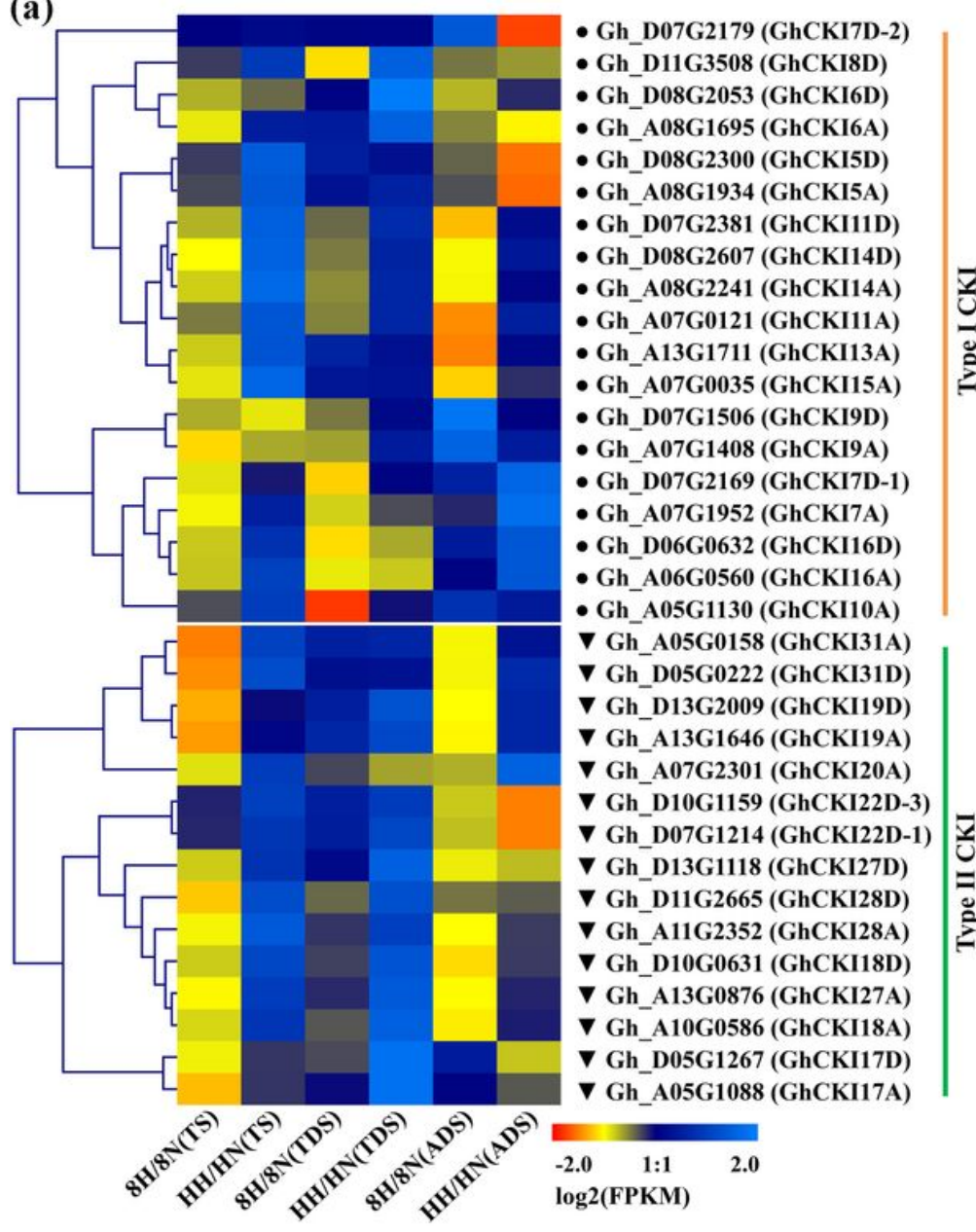

(b)
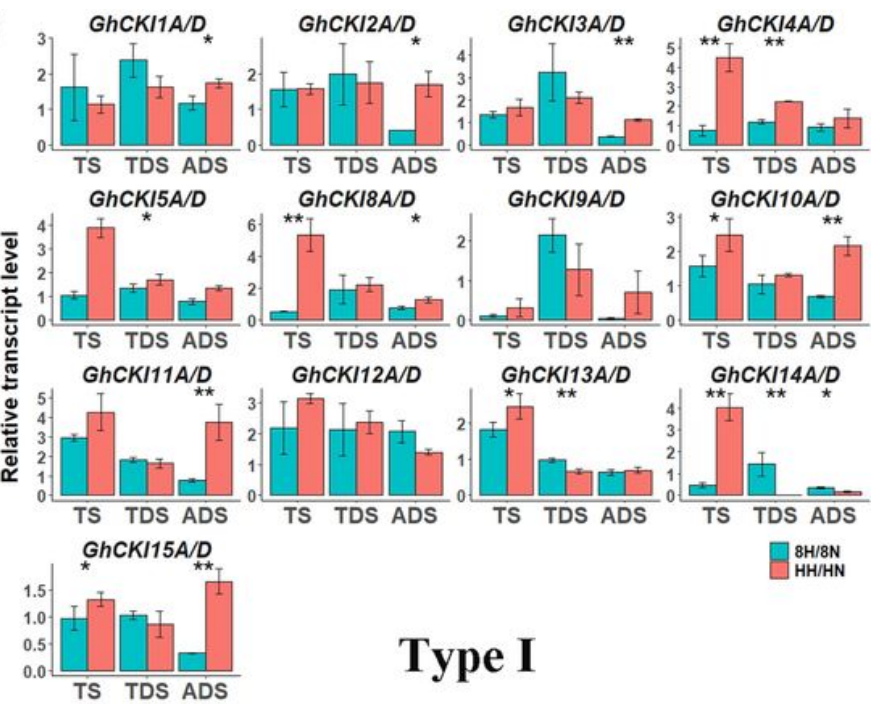

Type I

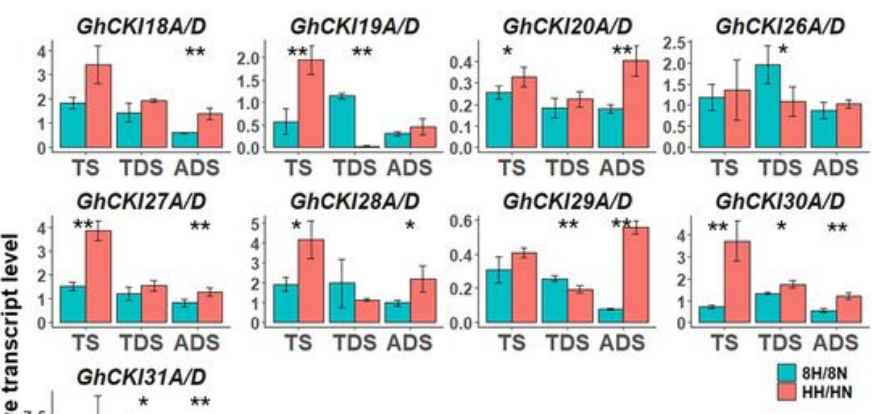

Type II

Figure 4

Expression profiles of $\mathrm{G}$. hirsutum CKI genes in anthers at different development stages under NT and HT conditions. (a-b) Expression patterns of G. hirsutum CKI genes in 84021 and $\mathrm{H} 05$ at different anther developmental stages under NT and HT conditions from RNAseq (a) and Quantitative RT-PCR experiment (b). $8 \mathrm{~N}$ and $8 \mathrm{H}$ refer to 84021 (the HT-tolerant line) under NT and HT conditions, respectively; HN and HH refer to H05 (the HT-sensitive line) under NT and HT conditions, respectively; TS: tetrads stage; TDS: tapetal degradation stage; FPKM: fragments per kb of transcript per million fragments mapped. The RNAseq data of the expression profiles was cited from Min et al. [30]. Error bars indicate \pm standard deviations of triplicate experiments. Asterisks indicate statistically significant differences $\left({ }^{*} P<0.05\right.$, $\left.{ }^{*} \mathrm{P}<0.01\right)$ by Student's t-test. The GhUB7 gene was used as the reference gene to normalize the total amount of cDNA in each reaction. 
(a)

(b)

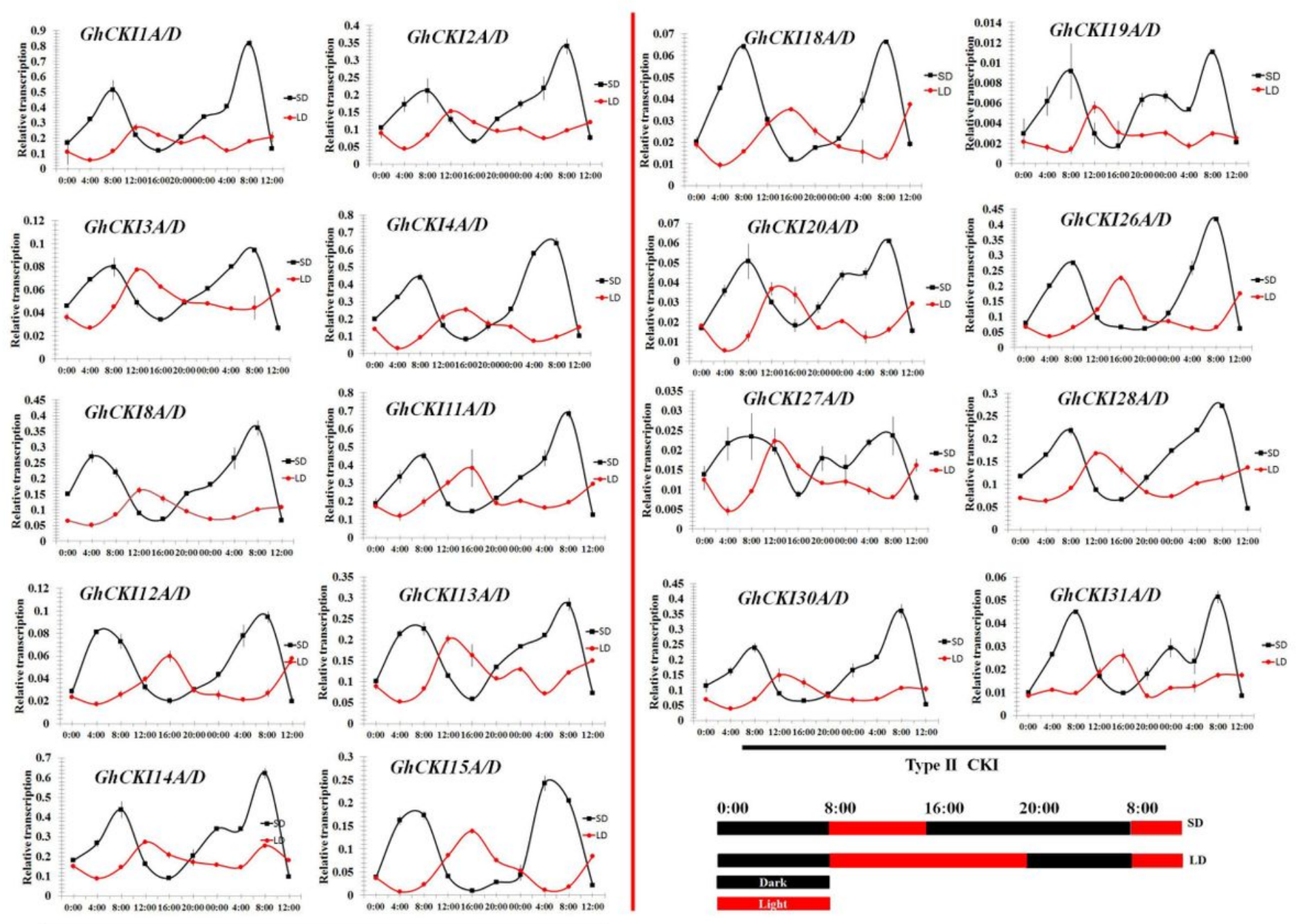

Type I CKI

Figure 5

Expression profiles of CKI genes under different diurnal conditions. (a) and (b) Expression profiles of the type I and type II CKI genes in G. hirsutum under different diurnal conditions, respectively. Diurnal changes in transcript levels of $36 \mathrm{G}$. hirsutum CKI genes under short-day (SD) and long-day (LD) conditions. SD, short day ( $8 \mathrm{~h}$ light); LD, long day (16 h light); Black boxes denote dark, while the solid red boxes show light. Values are means \pm standard deviations. Asterisks indicate statistically significant differences $\left({ }^{*} P<0.05,{ }^{*} \mathrm{P}<0.01\right)$ by Student's $t$ test. The Gh18S gene was used as the reference gene to normalize the total amount of cDNA in each reaction. 
(a)
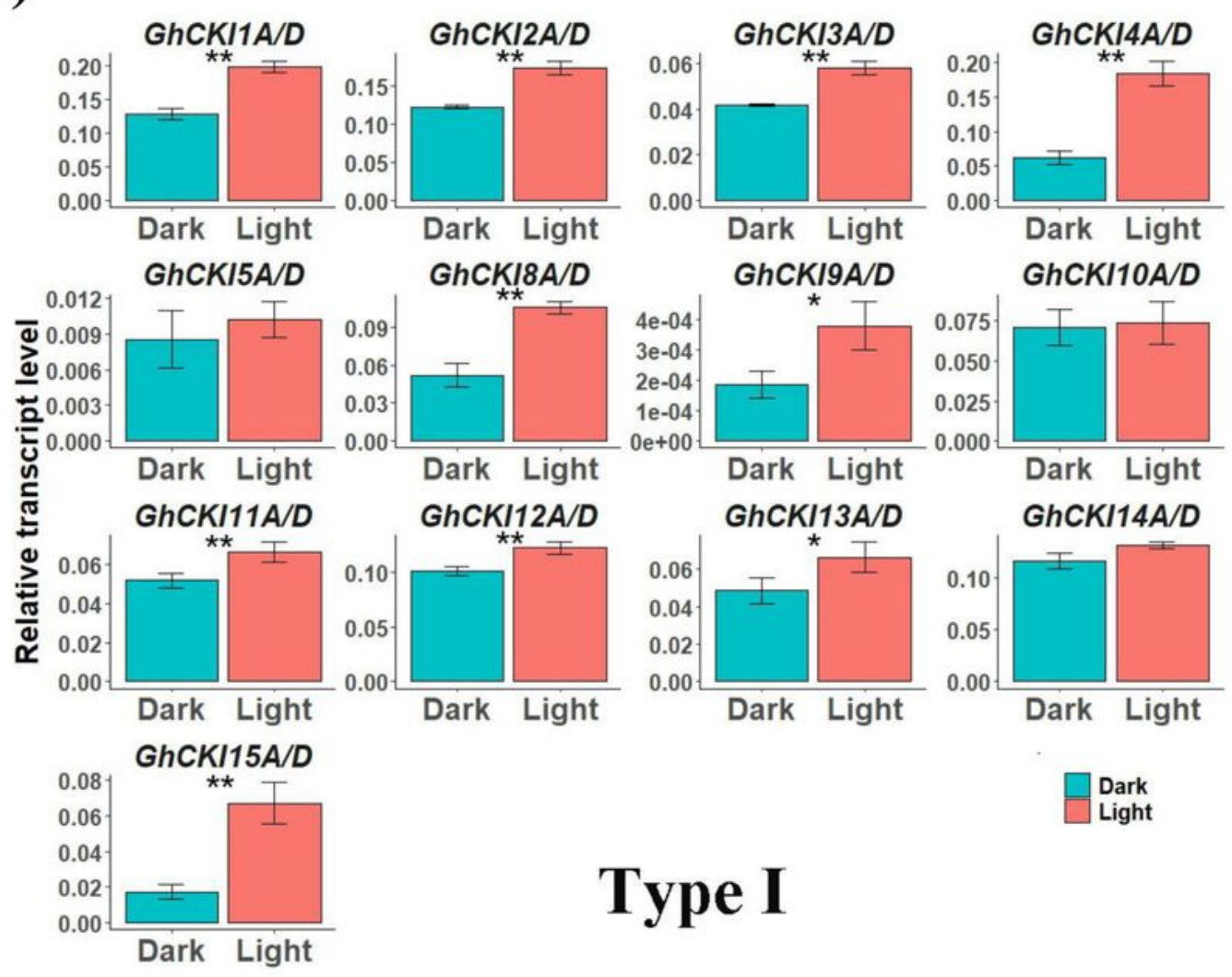

(b)
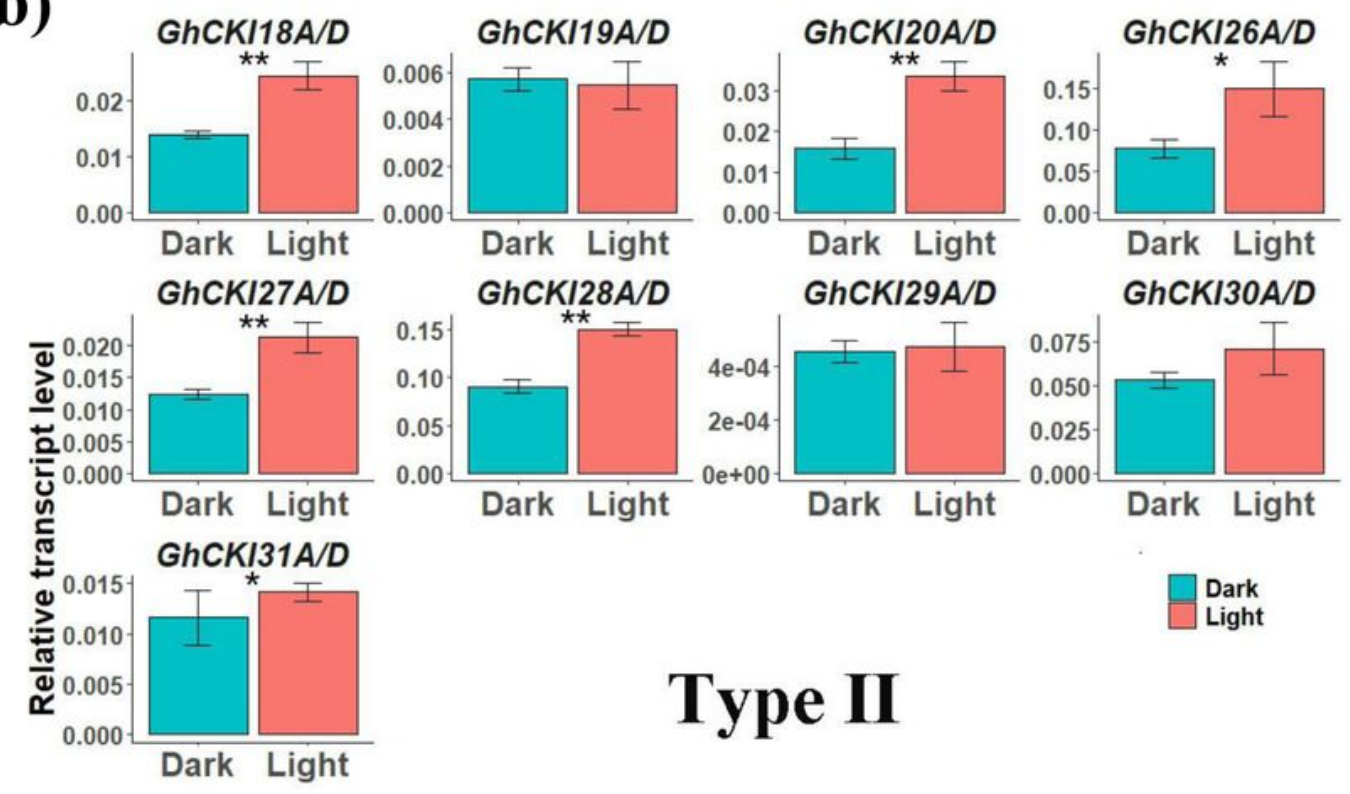

Type II

\section{Figure 6}

Expression profiles of GhCKI genes under dark and light conditions. (a) and (b) Expression profiles of the type I GhCKI genes (26 genes) and type II GhCKI genes (18 genes) in upland cotton cotyledons under dark and light conditions, respectively. Error bars indicate \pm standard deviations of triplicate experiments. Asterisks indicate statistically significant differences $\left({ }^{*} P<0.05\right.$, $\left.{ }^{\star *} P<0.01\right)$ by Student's t-test. The GhUB7 gene was used as the reference gene to normalize the total amount of cDNA in each reaction. 


\section{Supplementary Files}

This is a list of supplementary files associated with this preprint. Click to download.

- Tables2.xlsx

- TableS3.xIsx

- TableS1.xlsx

- Additionalfile1.pdf

- Table1.xlsx 